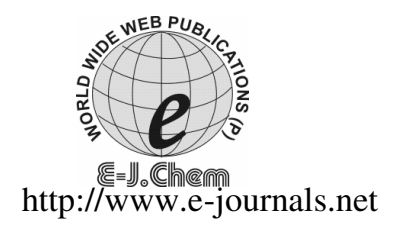

\title{
Thiazolidinone Steroids Impregnated Polyurethane Foams as a Solid Phase Extractant for the Extraction and Preconcentration of Cadmium(II) from Industrial Wastewater
}

\author{
MOHAMMAD S. TAWFIQ MAKKI*, R. MOHAMMADY ABDEL-RAHMAN, \\ K. OMMAR ALFOOTY and MOHAMMAD S. EL-SHAHAWI ${ }^{\S}$ \\ Department of Chemistry, Faculty of Science, King Abdulaziz University \\ P. O. Box 80203 Jeddah 21589, Kingdom of Saudi Arabia \\ ${ }^{\S}$ Department of Chemistry \\ Faculty of Science at Damiatta, Mansoura University, Mansoura, Egypt \\ mmakki@kau.edu.sa
}

Received 4 July 2010; Accepted 3 September 2010

\begin{abstract}
Two new thiazolidinone steroids namely sulfadiazino-imino- steroid (I) and 3-sulfonamoyl-phenyl-spiro[4-oxo-thiazolidin-2, 2`steroid] (II) were prepared and characterized from their molecular weight determination and spectroscopic measurements. Compound II were physically immobilized onto polyurethane foams (PUFs) for the preconcentration of cadmium(II) from acidic aqueous media containing iodide ions. The kinetics of the retention step of cadmium(II) from aqueous solutions by compound II treated PUFs was studied. Particle diffusion was the most probable operating mechanism and did not control the kinetics of cadmium(II) retention by compound II immobilized PUFs. A preconcentration / separation procedure is presented for the solid phase extraction of trace cadmium(II) from aqueous media as its ternary complex ion associate with compound II in industrial wastewater samples onto compound II treated PUFs prior to determination by flame atomic absorption spectrometry (FAAS). Compound II treated PUFs sorbent was successfully packed in glass column for complete extraction and / or determination of trace concentrations of cadmium(II) in wastewater samples with satisfactory recovery $(95 \pm 2.6)$. The cyclic voltammetry of compound II showed two well defined irreversible redox couples and suggested its possible use as complexing agent in stripping voltammetric determination of trace concentrations of toxic metal ions in wastewater.
\end{abstract}

Keywords: Cadmium(II), Thiazolidinone steroids, Removal, Determination, Polyurethane foam sorbent, Wastewater. 


\section{Introduction}

Water pollution by cadmium species is of considerable concern, as this metal has found widespread use in various industries ${ }^{1}$. The industrial effluents of many industries $e . g$. batteries, electroplating, leather tanning, nuclear power plant contain cadmium(II) at concentrations ranging from ten to hundreds of $\mathrm{mg} / \mathrm{L}^{2,3}$. It has been reported that, cadmium causes liver and lung cancer and kidney damage in humans and also it is toxic to other to other organism as well ${ }^{3}$.

Over the years, a variety of solid sorbent e.g. PUFs, cellulose, chromosorb-106 resin, Dowex $50 \mathrm{~W}-\mathrm{X} 4$, etc. immobilized with various chelating agents have been developed and applied successfully for preconcentration and subsequent determination of trace and ultra trace concentrations of metal ions in water samples ${ }^{4}$. Thiazolidin -4-one derivatives have received considerable attention because their compounds have shown excellent biological and pharmacological activity as plant protection agents against bacteria and fungi ${ }^{5,6}$. The basic properties of the thiazolidin -4-one derivatives increase in the orders: $\mathrm{NH}<\mathrm{S}<=\mathrm{O}$. Thus, this class of compounds facilitates the formation of complexes with various toxic heavy metal ions even if they were present at trace and ultra trace concentrations of in wastewater ${ }^{6,7}$.

Recent literature survey has revealed no use of the spiro-thiazolidinone reagents for separation and / or determination of trace concentrations of toxic metal ions in water and other complex matrices. Thus, in continuation to our previous work involving the use of PUFs sorbent ${ }^{8-14}$, the present article is focused on : i) synthesis of sulfodiazino-imino-steriod (I) and 3-sulfonamoylphenyl-spiro[4-oxo-thiazolidin-2,2`steroid (II); ii) studying the kinetics of the retention step of cadmium(II) from aqueous by the used solid PUFs sorbent in an attempt to develop low cost and effective preconcentration and / or determination method for trace and ultra trace concentrations of cadmium(II) in industrial wastewater samples using reagent physically treated PUFs in packed column and finally; iii) studying the voltammetric behavior of both steroids I and II (Figure.1) for suggesting cathodic stripping voltammetric procedures for determination of ultra trace concentrations of trace heavy metal ions in wastewater samples.

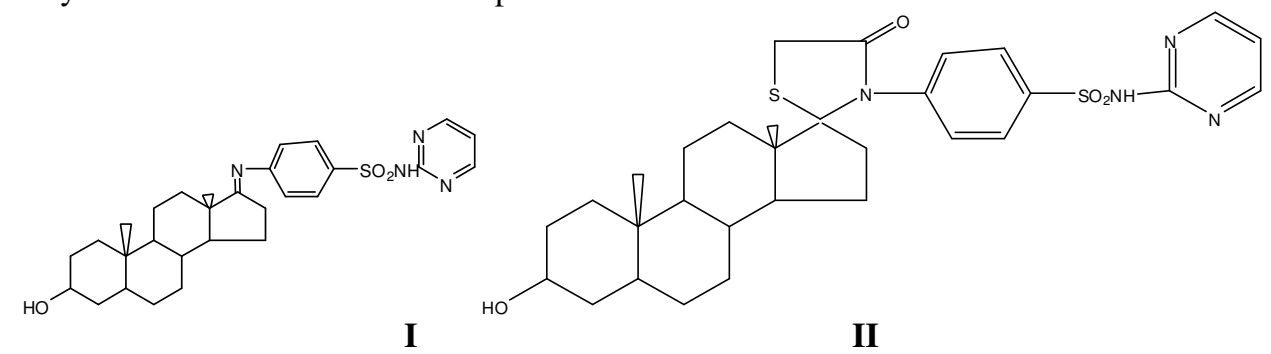

Figure 1. Chemical structures of sulfadiazine- imino- steroid (I) and spiro 4-thiazolidinone2, 2-steroid (II)

\section{Experimental}

All chemicals used were of analytical reagent grade and were used without further purification. Most of the chemicals were provided by Merck (Darmstadt, Germany). Doubly de ionized water was used throughout the work. A.R grade sulfanilamide, tetraethyl ammonium tetra fluoroborate (TEAB), solvents and epiandrosterone (Fluka AG, USA) were used as received. The sample solution was stored in low density polyethylene (LDPE) bottles and stored at -20 ${ }^{\circ} \mathrm{C}$ in a freezer. Stock solution $(0.1 \% \mathrm{w} / \mathrm{v})$ of the steroid compound I or II was prepared in ethanol. A stock solution of $\mathrm{CdCl}_{2}(1 \mathrm{mg} / \mathrm{mL})$ was prepared by dissolving an accurate weight $(0.1630 \pm 0.001 \mathrm{~g})$ of the salt in doubly distilled water $(100 \mathrm{~mL})$. 


\section{Apparatus}

A Perkin Elmer (Lambda EZ-210) double beam spectrophotometer $(190-1100 \mathrm{~nm})$ with $1 \mathrm{~cm}$ (path width) was used for recording the electronic spectra of the prepared solutions. A Perkins Elmer model RXI-FT-IR system 55529 was used for recording the IR spectra of the prepared compounds. A Brucker advance DPX $400 \mathrm{MHz}$ model using TMS as an internal standard was used for recording the ${ }^{1} \mathrm{HNMR}$ spectra of the compounds on deuterated DMSO. A GC- MS- QP 1000-Ex model was used for recording the mass spectra of the compounds. Mass spectra were recorded on Kartos $(75 \mathrm{eV}) \mathrm{M} / \mathrm{S}$ equipment. A Perkin-Elmer (Analyst TM 800, USA) atomic absorption spectrometer (AAS) was used for measuring the concentration of cadmium ions before and after extraction at 242 at the optimum operational parameters of the instrument. Deionized water was obtained from Milli-Q Plus system (Millipore, Bedford, MA, USA) was used for preparing all solutions. A pH meter (Orion EA940, MA, USA) was employed for the $\mathrm{pH}$ measurements with absolute accuracy limits at the $\mathrm{pH}$ measurements being defined by NIST buffers. An electrothermal Bibbly Stuart Scientific Melting Point SMPI (US) was used for recording the melting point. Molecular weights of the compounds were preformed on Micro analytical center, Cairo University, Egypt. Digital pH-meter (model MP220, Metter Toledo) was used for $\mathrm{pH}$ measurements. A Metrohm 746 VA trace analyzer and 747 VA stand were used for recording the electrochemical experiments. A three-compartment borosilicate (Metrohm) voltammetric cell $(10 \mathrm{~mL})$ incorporating hanging mercury dropping electrode (HMDE, drop surface area $\left.0.38 \mathrm{~mm}^{2}\right)$ as working, $\mathrm{Ag} / \mathrm{AgCl},(3 \mathrm{M} \mathrm{KCl})$, as a reference and Pt wire (BAS model MW1032) as counter electrodes, respectively was used for recording the cyclic voltammetry of the tested compounds $\mathbf{I}$ and $\mathbf{I I}$ in $\mathrm{N}, \mathrm{N}$-dimethylformamide solvent in the presence of TEAB.

\section{Synthesis of sulfodiazino-imino-steriod $(\boldsymbol{I})$}

Compound I was prepared according to the following method. A mixture of sulfadiazine drug $(0.01 \mathrm{~mol})$ and the steroid epiandrosterone $(0.01 \mathrm{~mol})$ in DMF $(50 \mathrm{~mL})$ was refluxed for $2 \mathrm{~h}$ and the resultant reaction mixture was cooled, poured on an ice bath. The solid formed was filtered off, washed several times with methanol, re crystallized from tetrahydrofuran and dried in vacuo (yield 55\%), m.p. $215^{\circ} \mathrm{C}$. Compound $\mathbf{I},\left(\mathrm{C}_{29} \mathrm{H}_{38} \mathrm{~N}_{4} \mathrm{SO}_{3}\right.$ ): molecular weight calculated 522, found 520; UV (DMF) $\lambda_{\max }(\log \varepsilon): 305 \mathrm{~nm}(1.95)$; selected IR: $v 3520(\mathrm{OH}), 3130\left(\mathrm{NHSO}_{2}\right), 2920,2890,2880$ (stretching of $\mathrm{CH}_{3}, \mathrm{CH}_{2}$ groups), $1640\left(\mathrm{C}=\mathrm{N}\right.$ ), 1480, 1440 (deforming of $\mathrm{CH}_{3}, \mathrm{CH}_{2}$ groups), 1350 (sulphonamido $\mathrm{SO}_{2} \mathrm{NH}_{2}$ group), 1255(exo C-N) and $810 \mathrm{~cm}^{-1}$ (p-substituted phenylz ${ }^{15,16} ;{ }^{1} \mathrm{H}$ NMR in $\mathrm{d}_{6}$-DMSO showed signals at $\delta: 0.8,1.2 .3 .5\left(\mathrm{CH}_{3}\right.$ of 18.19 and $3 \alpha-\mathrm{H}$ of steroid $), 2.8\left(\mathrm{NH} \mathrm{SO}_{2}\right), 7.6-$ $7.9 \mathrm{ppm}$ ( $\mathrm{m}, 4 \mathrm{H}$ of aryl and of pyrimidine protons); $\mathrm{M} / \mathrm{S}(\mathrm{m} / \mathrm{z}): 522\left(\mathbf{M}^{+}+2\right)$.

\section{Synthesis of 3-sulfonamoylphenyl-spiro [4-oxo-thiazolidin-2, 2`steroid (II)}

Compound II was prepared as follows: An accurate weight of the imino derivative (I), $(0.01$ $\mathrm{mol})$ and thioglycolic acid $(0.05 \mathrm{~mol})$ in dry dioxan $(100 \mathrm{~mL})$ were refluxed for $8 \mathrm{~h}$, left to cool and poured onto an ice- $\mathrm{NaHCO}_{3}$. The solid formed was washed several times with methanol, re crystallized from tetrahydrofuran and dried in vacuo (yield $78 \%$ ), m.p. $185{ }^{\circ} \mathrm{C}$ to give II. Compound II, $\left(\mathrm{C}_{31} \mathrm{H}_{40} \mathrm{~N}_{4} \mathrm{~S}_{2} \mathrm{O}_{4}\right)$ : molecular weight calculated = 596, found 593; UV (DMF) $\lambda_{\max }(\log \varepsilon): 335(0.5), 305 \mathrm{~nm}(1.5)$; selected spectroscopic data IR: $v$ 1660, 1330 (cyclic $\mathrm{C}=\mathrm{O}$ NCS), 2950, 2880 (stretching of $\mathrm{CH}_{3}, \mathrm{CH}_{2}$ groups), $1200 \mathrm{~cm}^{-1}(\mathrm{C}-\mathrm{S})^{17,18}$; ${ }^{1} \mathrm{HNMR}$ in $\mathrm{d}_{6}$-DMSO showed signals at $\delta: 3.7\left(2 \mathrm{H}, \mathrm{S}-\mathrm{CH}_{2}\right), 0.8,1.5,3.5\left(\mathrm{CH}_{3}\right.$ of 18.19 and $3 \alpha-\mathrm{H}$ of steroid), $3\left(\mathrm{NH} \mathrm{SO}_{2}\right), 6.9-7.9 \mathrm{ppm}(\mathrm{m}, 4 \mathrm{H}, 3 \mathrm{H}$ of pyrimidine and aryl protons); $\mathrm{M} / \mathrm{S}(\mathrm{m} / \mathrm{z}): 593\left(\mathrm{M}^{+}+2\right)$. 


\section{Preparation of the compound II treated polyurethane foams}

The compound II $(1 \% \mathrm{w} / \mathrm{v})$ in water was shaken with the PUFs cubes in the presence of the plasticizer TOA $(1 \% \mathrm{v} / \mathrm{v})$ with efficient stirring for $30 \mathrm{~min}$. The loaded II PUFs cubes were squeezed and dried between two filter papers ${ }^{12}$. The amount (a) of II retained onto the PUFs sorbent was calculated using the equation ${ }^{11,12}$ :

$$
a=\left(\mathrm{C}_{\mathrm{o}}-\mathrm{C}\right) \frac{\mathrm{v}}{\mathrm{W}}
$$

Where, $\mathrm{C}_{\mathrm{o}}$ and $\mathrm{C}$ are the initial and final concentrations ( $\mathrm{mol} \mathrm{L}^{-1}$ ) of the compound $\mathbf{I I}$ in solution respectively, $v=$ volume of the reagent solution (liter) and ' $w$ ' is the mass ( $g$ ) of the PUFs sorbent.

\section{Recommended batch extraction procedures}

An accurate weight $(0.1 \pm 0.002 \mathrm{~g})$ of the compound II immobilized PUFs was equilibrated with an aqueous solution $(100 \mathrm{~mL})$ containing cadmium $\left(5.0 \mu \mathrm{g} \mathrm{mL}^{-1}\right)$ in the presence of KI $(10 \% \mathrm{w} / \mathrm{v})$, at various $\mathrm{pH}$. The test solutions were shaken for $1 \mathrm{~h}$ on a mechanical shaker and the aqueous phases were then separated out by decantation. The amount of cadmium(II) remained in the aqueous phase was then determined by FAAS. The amount of cadmium(II) retained on the foam cubes was then calculated from the difference between the concentration of cadmium(II) in the test aqueous solutions before $\left(\mathrm{C}_{\mathrm{b}}\right)$ and after extraction $\left(\mathrm{C}_{\mathrm{f}}\right)$. The sorption percentage $(\% \mathrm{E})$, the amount of cadmium(II) retained at equilibrium $\left(\mathrm{q}_{\mathrm{e}}\right)$ per unit mass of solid sorbent $(\mathrm{mol} / \mathrm{g})$ and the distribution coefficient $\left(\mathrm{K}_{\mathrm{d}}\right)$ of sorbed analyte onto the foam cubes were finally calculated as reported. The $\% \mathrm{E}$ and $\mathrm{K}_{\mathrm{d}}$ are the average of three independent measurements and the precision in most cases was $\pm 2 \%$. Following these procedures, the influence of shaking time and reagent concentration treated PUFs on the retention step of cadmium(II) by the tested PUFs sorbents was studied.

\section{Recommended chromatographic separation}

An aqueous solution $(100 \mathrm{~mL})$ containing cadmium(II) ions at concentration $(5,10 \mu \mathrm{g}$ $\left.\mathrm{mL}^{-1}\right)$, KI $(10 \%)$ and $\mathrm{H}_{2} \mathrm{SO}_{4}\left(0.01 \mathrm{~mol} \mathrm{~L}^{-1}\right)$ was percolated through the $\mathrm{PQ}^{+} \mathrm{Cl}^{-}$loaded PUFs $(1.0 \pm 0.01 \mathrm{~g})$ packed column at $5.0 \mathrm{~mL} \mathrm{~min}^{-1}$ flow rate. A blank experiment was also performed in the absence of cadmium(II) ions. Cadmium(II) sorption took place quantitatively as indicated from the analysis of cadmium species in the effluent solutions by FAAS. Cadmium(II) was quantitatively recovered with $\mathrm{HNO}_{3}(25 \mathrm{~mL}, 1.0$

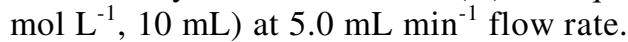

\section{Results and Discussion}

\section{Spectroscopic characterization of compounds I and II}

Spiro-thiazolidinones have been reported to posse's considerable pharmaceutical potentialities ${ }^{16-20}$. Therefore, the present article is focused on the synthesis of two new compounds I \& II derived from sulfadiazine drug for their use as suitable complexing agents for stripping voltammetric determination and separation of toxic metal ions in wastewater samples. Condensation of the sulfadiazine drug with ketonic steroid epiandrosterone in boiling DMF ${ }^{17,18}$ yielded $\mathbf{I}$, which upon cycloaddition reactions with thioglycolic acid in dry dioxan ${ }^{17-19}$ led to the direct formation of II. The structure of obtained compounds was established from their molecular weight determination and spectroscopic data 


\section{Retention profile of cadmium(II) onto compound immobilized PUFs}

Preliminary batch experiments employing the compounds I and II immobilized polyurethane foams (PUFs) for the uptake of trace concentrations of cadmium(II) ions from the aqueous solutions containing excess of $\mathrm{KI}(5 \% \mathrm{w} / \mathrm{v})-\mathrm{H}_{2} \mathrm{SO}_{4}(.0 .01 \mathrm{M})$ revealed considerable retention of cadmium(II) by the latter reagent. Thus, the preconcentration of cadmium(II) ions from the aqueous $\mathrm{KI}-\mathrm{H}_{2} \mathrm{SO}_{4}$ solutions onto the compound II immobilized PUFs as solid sorbent was critically investigated. The results revealed the dependence of cadmium(II) uptake from the test aqueous solution depends on the solution $\mathrm{pH}$. Thus, the effect of the aqueous solution containing excess of $\mathrm{KI}(5 \% \mathrm{~m} / \mathrm{v})$ at different $\mathrm{pH}(\mathrm{pH} \mathrm{3-10)}$ on the retention of cadmium(II) ions at reasonable concentration $\left(5.0 \mu \mathrm{g} \mathrm{mL}^{-1}\right)$ by the immobilized PUFs was investigated. After shaking the test solutions of one hour, the amount of cadmium(II) remained in the aqueous solution was determined by flame atomic absorption spectrometry (FAAS). The results indicated that, the uptake of cadmium(II) onto the loaded PUFs decreased on raising the solution $\mathrm{pH}$ and maximum sorption percentage was achieved at $\mathrm{pH} \sim 3$ (Figure 2). The retention of cadmium(II) by the immobilized compound II treated PUFs at $\mathrm{pH} \sim 3$ is most likely attributed to the formation of the anionic complex species $\left[\mathrm{CdI}_{4}\right]^{-2}$ in the aqueous phase and subsequent formation of ternary ion associate $\left[\left(\mathrm{II}^{+}\right)_{2} \cdot\left(\mathrm{CdI}_{4}\right)^{-2}\right]$ involving the steroid compound(II) and the anion $\left[\mathrm{CdI}_{4}\right]^{-2}$ on / in the PUFs membrane. The protonation of the available binding sites in the PUFs i.e. ether and / or urethane linkages may also participate in the formation of an ion associate with the anion $\left[\mathrm{CdI}_{4}^{-2}\right]$ at the solution of $\mathrm{pH} 3$. The formation of the anion $\left[\mathrm{CdI}_{4}\right]^{-2}$ and the protonation of the sorbent sites enhanced the retention of the ion associate $\left[\left(\mathrm{II}^{+}\right)_{2} \cdot\left(\mathrm{CdI}_{4}\right)^{-2}\right]$ on/ in the solid PUFs via a "solvent extraction" and /or weak base anion exchange mechanism". Similar trend has been reported for the retention of some anionic complex species of cadmium(II) by methyl isobutyl ketone and some other solvents that posses ether linkages in their structures $e$.g. diethyl ether, isopropyl ether and polyurethane ether -type foams ${ }^{20,21}$.

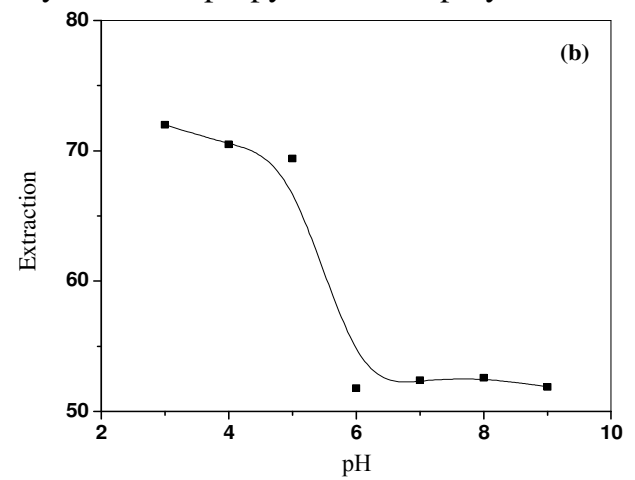

Figure 2. Effect of $\mathrm{pH}$ on the sorption profile of cadmium(II) from aqueous KI media $(1 \% \mathrm{~m} / \mathrm{v})$ onto compound II treated PUFs after $1 \mathrm{~h}$ shaking time at room temperature.

The influence of the compound(II) concentration (0.01-0.05\% w/v) immobilized PUFs on the extraction of cadmium(II) at $\mathrm{pH} 3$ and shaken for $1 \mathrm{~h}$ showed a significance preconcentration of cadmium(II) from aqueous media. Maximum cadmium(II) uptake was achieved at $0.02 \%(\mathrm{w} / \mathrm{v})$ reagent immobilized PUFs cubes. The amount of the reagent immobilized is good enough to retain considerable concentration from the test aqueous solution. Therefore, on the subsequent work, the reagent loaded foams were adjusted at concentration of $0.01 \%(\mathrm{w} / \mathrm{v})$. 


\section{Kinetics of cadmium(II) retention onto the compound II loaded PUFs}

The sorption of cadmium(II) ions onto the steroid II immobilized PUFs sorbents was found to depend on shaking time and cadmium(II) uptake was fast and reached equilibrium at 20 min shaking time. This conclusion was supported by the values of the half-life time $\left(t_{1 / 2}\right.$ $\left(\mathrm{t}_{1 / 2}=2 \mathrm{~min}\right)$ of cadmium(II) sorption by the reagent immobilized PUFs (Figure 3 ). Thus, gel diffusion is not only the rate-controlling step for both sorbents as in the case of common ion exchange resins ${ }^{20-22}$. Therefore, the kinetic behavior of cadmium(II) sorption onto the immobilized PUFs sorbents depends on film diffusion and intra particle diffusion and the more rapid one will control the overall rate of transport. The retention of cadmium(II) species onto the used immobilized reagent PUFs was subjected to Weber - Morris model ${ }^{22}$ as follow:

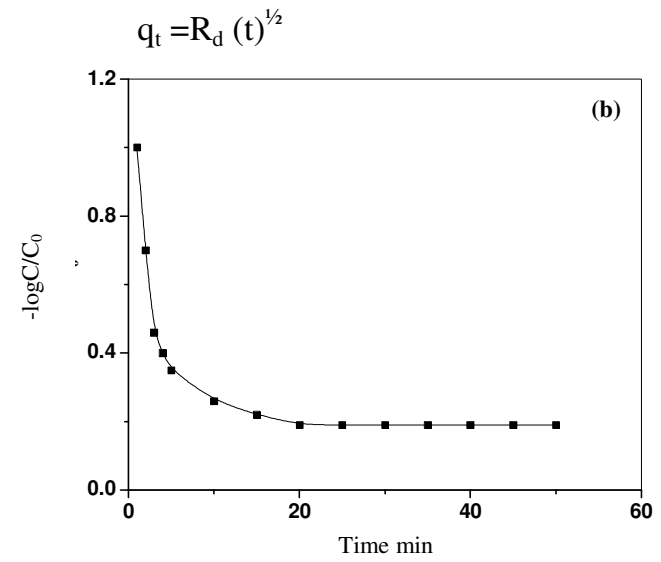

Figure 3. Rate of sorption of cadmium(II) onto reagent immobilized foams at $20 \pm 0.10{ }^{\circ} \mathrm{C}$.

Where, $R_{d}$ is the rate constant of intra-particle transport in mmol g $\min ^{-1 / 2}$ and $q_{t}$ is the sorbed cadmium(II) concentration (mol. $\mathrm{g}^{-1}$ ) at time $\mathrm{t}$. The plots of $\mathrm{q}_{\mathrm{t}}$ versus time were found linear with correlation coefficient in the range of $\mathrm{R}^{2}=0.975-0.980$ in the initial stage of shaking time (up to 4-5 min) for cadmium(II) retention onto the reagent immobilized PUFs sorbents and deviate on increasing the shaking time. In the initial stage, the diffusion rate was high and decreased on passage of time indicating that the rate of the retention step is film diffusion at the early stage of extraction ${ }^{23,24}$. The values of $R_{d}$ were found equal $0.67 \mathrm{~mol} . \mathrm{g}^{-1} \cdot \mathrm{min}^{-1 / 2}$ for reagent immobilized PUFs in the initial stage up to $4.0 \mathrm{~min}$ of agitation time, respectively. Beyond 4-5 min shaking time, the values of $R_{d}$ for immobilized PUFs towards retention of cadmium(II) from the aqueous solution reduced to $0.23 \mathrm{~g}^{-1} \cdot \mathrm{min}^{-1 / 2}$, respectively. The change in the slope for the reagent immobilized polyurethane foams is most likely due to the existence of different pore $\operatorname{sizes}^{23,24}$ on the used solid sorbents and confirm that, the intra-particle diffusion step can be a rate controlling step.

The sorption of cadmium(II) onto the reagent loaded foams was also subjected to Lagergren kinetic model over the entire range of agitation time. The Lagergren model can be expressed by the following equation ${ }^{25}$ :

$$
\log \left(\mathrm{q}_{\mathrm{e}}-\mathrm{q}_{\mathrm{t}}\right)=\log \mathrm{q}_{\mathrm{e}}-(\mathrm{kt} / 2.303)
$$

Where, $\mathrm{q}_{\mathrm{e}}$ represents the sorbed concentration of cadmium(II) onto the PUFs sorbent at equilibrium $\left(\mathrm{mol}^{-1} \mathrm{~g}^{-1}\right)$ and $\mathrm{k}$ is the over all first order rate constant. The plots of $\log \left(\mathrm{q}_{\mathrm{e}}-\mathrm{q}_{\mathrm{t}}\right)$ versus time up to 30 min were found linear. The values of the $\mathrm{k}$ calculated from the slopes of linear plot given was found equal $0.22 \pm 0.0001$ These data confirm that, particle diffusion is 
the most probable operating mechanism and does not control the kinetics of cadmium(II) sorption onto the immobilized foams. Thus, the retention of cadmium(II) onto PUF cubes involves three steps: i) bulk transport of cadmium(II) in solution; ii) film transfer involving diffusion of cadmium(II) species within the pore volume of PUF and/or along the pore wall surface to an active sorption site $e^{23,24}$ and finally; iii) formation of the ternary complex ion associate of the formula $\left[-\mathrm{CH}_{2}-{ }^{+} \mathrm{OH}-\mathrm{CH}_{2}\right]$. $\left[\mathrm{CdI}_{4}\right]^{-2}$ foam and $\left[-\mathrm{CH}_{2}{ }^{+} \mathrm{OH}-\mathrm{CH}_{2}\right]\left[\mathrm{CdI}_{4}^{-2} \mathrm{R}^{+}\right]_{\text {foam }}$ where $\mathrm{R}^{+}=$reagent. Therefore, the actual sorption of $\left[\mathrm{CdI}_{4}^{-2}\right]$ onto the interior surface is rapid and hence it is not the rate determining step in the sorption process. Thus, one may conclude that, film and intra-particle transport might be the two main steps controlling the sorption step. Thus, "solvent extraction" or a "weak base anion ion exchanger" mechanism is not only the most probable participating mechanisms and most likely, some other processes like specific sites on the PUFs are possibly involved simultaneously in the cadmium retention from the bulk aqueous solution on the solid sorbent.

\section{Analytical application}

The validation of the compound II immobilized PUFs solid sorbent was successful assessed by using the compound II immobilized PUFs in packed column for collection of various concentrations $\left(100 \mathrm{~mL}, 30-100 \mu \mathrm{gL}^{-1}\right)$ of cadmium(II) in de ionized water. The sample solutions were percolated through the PUFs packed column at $5-10 \mathrm{~mL} \mathrm{~min}^{-1}$ flow rate. Complete retention of cadmium was achieved onto PUFs packed column as indicated from the absence of cadmium in the effluent by FAAS.

The retention of cadmium(II) from industrial wastewater was also carried out following the same procedures. The water samples of industrial wastewater $(0.5 \mathrm{~L})$ of electroplating industry after acidified with phosphoric acid was spiked with various concentrations $\left(5,10 \mu \mathrm{gmL}^{-1}\right)$ of cadmium(II), acidified with phosphoric acid and filtered through a $0.45 \mu \mathrm{m}$ cellulose membrane filter. The test water samples were percolated through the reagent

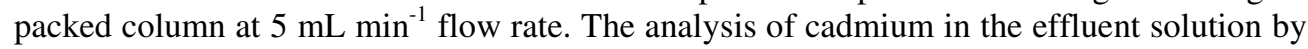
FAAS revealed complete retention of cadmium from the test solution. The results are summarized in Table 1. Cadmium was quantitatively recovered with nitric acid (25 mL, $1.0 \mathrm{M})$ and analyzed by FAAS. A satisfactory recovery percentage of total cadmium was achieved in the range $95.0 \pm 2.6$.

Table 1. Analytical results for the preconcentration and recovery of cadmium(II) in wastewater samples by the compound II immobilized PUFs packed column

\begin{tabular}{ccc}
\hline \multicolumn{2}{c}{ Cadmium(II) species } & Recovery, ${ }^{*}$ \\
\hline Added, $\mu \mathrm{g} / \mathrm{mL}$ & Found, $\mu \mathrm{g} / \mathrm{L}$ & \\
5.0 & 4.8 & $96.0 \pm 1.8$ \\
10.0 & 9.4 & $94.0 \pm 2.7$ \\
\hline
\end{tabular}

*Average \pm relative standard deviation

\section{Voltammetric behavior of the tested compounds I and II}

Cyclic voltammograms (CVs) of the two steroids I and II in DMF- TEAB at the hanging mercury drop electrode (HMDE) versus $\mathrm{Ag} / \mathrm{AgCl}$ reference electrode at various scan rates were critically carried out. Representative CVs of II are shown in Figure 2. The CV of II (Figure 4) at various scan rates showed one well defined reduction wave in the range -0.32 $(-0.35)$ (Peak I) and two ill defined reduction peaks in the range -0.55- (-057) and -0.64 68 versus $\mathrm{Ag} / \mathrm{AgCl}$. On the reverse scan, no anodic peaks were observed suggesting irreversible nature of the electrochemical processes ${ }^{27}$. 


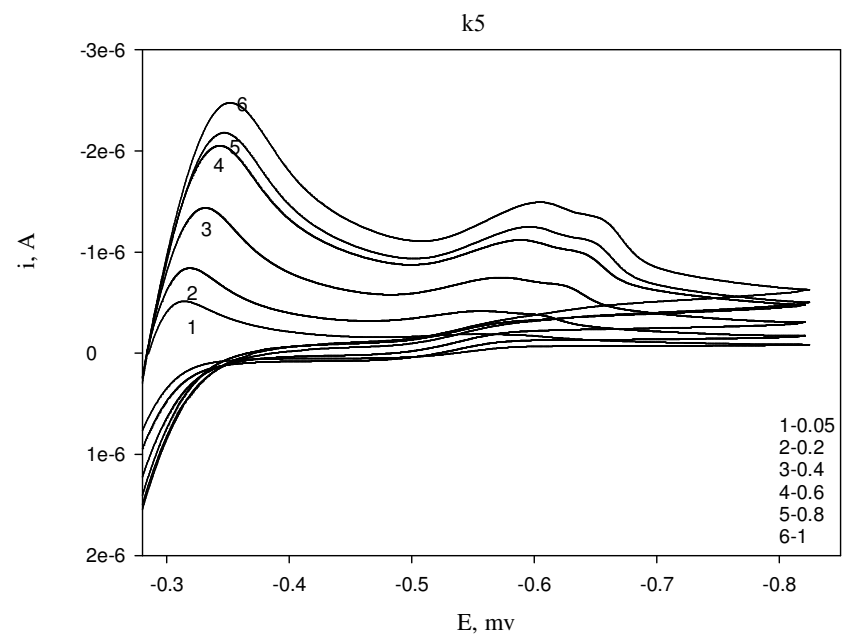

Figure 4. CVs of II in DMF-THAC at HMDE versus $\mathrm{Ag} / \mathrm{AgCl}$ electrode at various scan rate.

The same observation was also confirmed from the progressive cathodic shift on increasing the scan rate confirming the irreversible nature of the reduction processes of the compound. The plot of the square root of the scan rate versus the corresponding cathodic peak current, $i_{p, c}$ of peak I increased linearly on increasing the scan rate, indicating that the electrochemical reduction process is a diffusion process. The CV of the steroid $\mathbf{I}$ in the potential range $0.0-(-1.0) \mathrm{V}$ revealed one well-defined cathodic peak (peak I) in the potential range $-0.34-(-0.37)$ and another ill defined cathodic peak at $-0.44-(-0.48) \mathrm{V}$ versus $\mathrm{Ag} / \mathrm{AgCl}$ electrode, while no anodic peaks were observed on the reverse scan, confirming also the irreversible nature of the two electrochemical reduction processes of the compound I. Continuous scan of the CV of compound I significantly decreased the peak current height and the signal is hardly discernible from the baseline, indicating passivity of the surface of the HMDE electrode via formation of polymeric oxidation product or fouling of the HMDE electrode by the reduction products ${ }^{26}$. The overall results suggest the possible use of the II as complexing agent in cathodic stripping voltammetry for determination of cadmium(II) ions(II) in water.

\section{Conclusion}

The use of II for the minimization and separation of trace and ultra trace metal ions in drinking and wastewater samples represents a great challenge in recent years. The voltammetric behavior of the two compounds I and II suggested the use of the compound II as chelating agent for differential pulse - cathodic stripping voltammetry for the determination and chemical speciation of ultra trace concentrations of heavy metal ions. Thus, work is continuing for preparing a chemically modified glassy carbon electrode with the compound II to be used in stripping voltammetric mode for the determination and chemical speciation of trace metal ions in e.g. cadmium(II), arsenic(III), antimony(III) and bismuth(III) etc. in water as reported ${ }^{27}$.

\section{Acknowledgment}

The authors would like to thank the Deanship of Scientific Research, King Abdul-Aziz University, Saudi Arabia for the financial support and funding under the grant number 9/11. 


\section{References}

1. Forstner U and Wittman G T W, Metals Pollution in the Aquatic Environment, Springer-Verglag, Berlin, Heidelberg, Germany, 1981.

2. Mertz W, Ed., Trace Elements in Human and Animal Nutrition, Academic Press, London, 1986.

3. Merian E, "Metals and Their Compounds in The Environment, Occurrence, Analysis and Biological References" VCH, 1980.

4. Pohl P and Prusisz B, Anal Chim Acta, 2004, 502, 83 and references cited therein.

5. Abdel-Rahman R M, Bull Chimico Farmaceutico, 2001, 140, 410.

6. Zaki M T, Abdel-Rahman R M and El-Sayed A Y; Anal Chim Acta., 1995, 307, 127-138.

7. Kozlowski C A, Ulewicz M, Walkowiak W, Girek, T and Jablonska J, Min Eng., 2002, 15, 677-682.

8. El-Shahawi M S and Almehdi M A, J Chromatogr A, 1995, 697(1-2), 185-190.

9. El-Shahawi M S and Nassif H A, Anal Chim Acta, 2003, 481, 29-39.

10. El-Shahawi M S, Abou-Mesalam M M, Abdel-Hai M S and El-Naggar I M, $J$ Radioanal Nucl Chem., 2003, 258, 619-625.

11. El-Shahawi M S, Othman M A and Abdel-Fadeel M A, Anal Chim Acta, 2005, 546, 221-228.

12. Farag A B, Soliman M H, Abdel-Rasouland O S and El-Shahawi M S, Anal Chim Acta, 2007, 601, 218.

13. El-Shahawi M S, Hassan S S M, Othman M A and El-Sonbati M A, Microchem J 2008, 89, 13.

14. Bashammakh A S, Bahaffi S O, Al-Shareef F M and El-Shahawi M S, Anal Sci Jpn., 2009, 25, 413-418.

15. Mukherjee K S and Mukhopadhyay B, J Indian Chem Soc.,.2005, 82, 936-937.

16. Duddeck H, Elgamal, M H A, Ricca G S, Danielli B and Palmisano G, Org Magn Resonance, 1978, 11, 130-139.

17. Shafiullah S, Siddiqui I H, Ansari S A, Khan E H and Shafi S, J Indian Chem Soc., 2000, 77, 215.

18. Abdel-Monem W R, Bull Chimico Farmaceutico, 2004, 143(10), 239-247.

19. Talapatra S K, Polley M and Talopatra B, J Indian Chem Soc.,1994, 71, 527-532.

20. El-Shahawi M S, Othman A M, Bashammakh A S and El-Sonbati M A Int J Environ Anal Chem., 2006, 86(12), 941.

21. Nambiar C H R, Narayana B, Rao B M, Mathew R and Ramachandra B, Microchem J., 1996, 53, 175.

22. Weber W J and Morris J C, J Sanit Eng Div Am Soc Civ Eng., SA2, 1963, 89, 31-60

23. Weber Jr W J and Morris J C, J Sanit Eng Div Am Soc Civ Eng., SA3, 1964, 90, 70.

24. Mukherjee K S and Mukhopadhyay B, J Indian Chem Soc., 2005, 82, 936-937.

25. Lagergren S and Sven B K, Vatenskapsakad Handl, 1898, 24.

26. Bard A J and Fulkner L R, Electrochemical Methods, Fundamentals and Applications Wiley, New York, 1980, 218-227.

27. Kadi M W and_El-Shahawi_M S, Radiochimica Acta, 2009, 97(11), 613-620. 


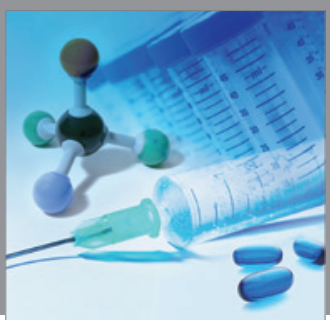

International Journal of

Medicinal Chemistry

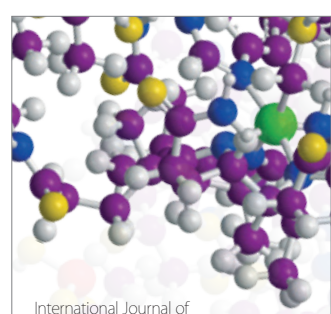

Carbohydrate Chemistry

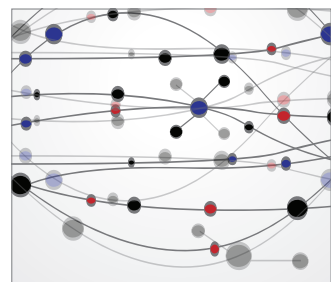

The Scientific World Journal
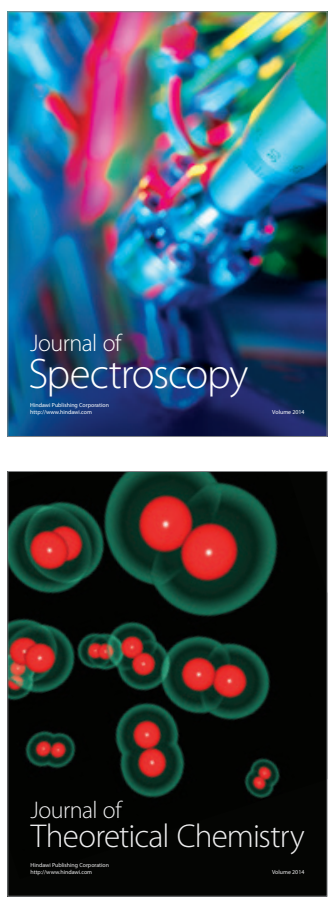
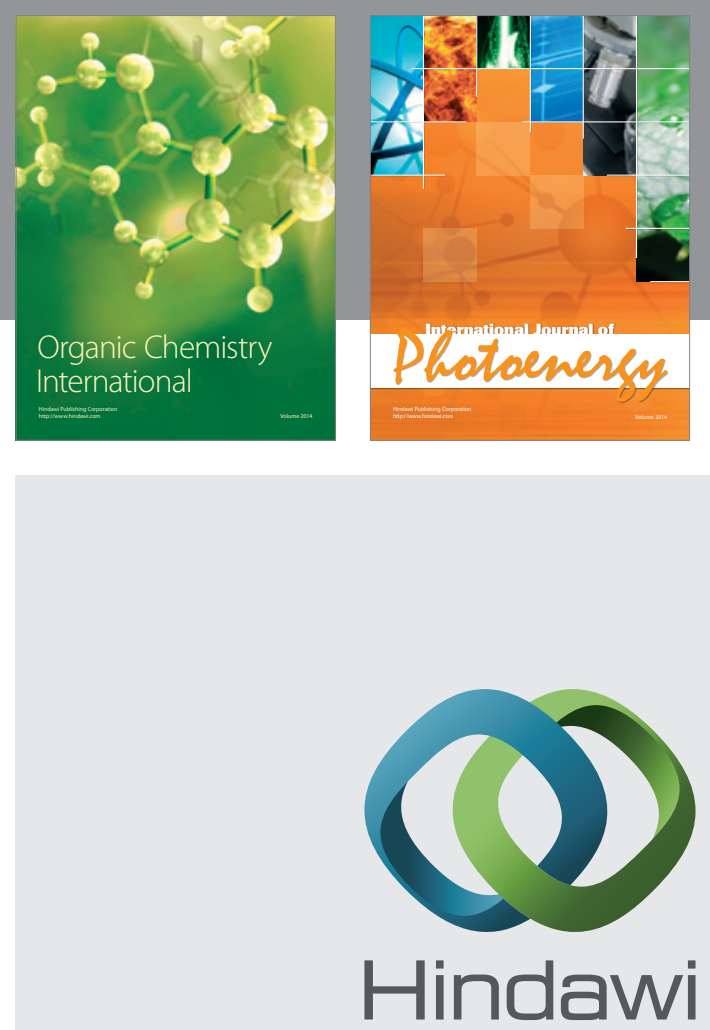

Submit your manuscripts at

http://www.hindawi.com
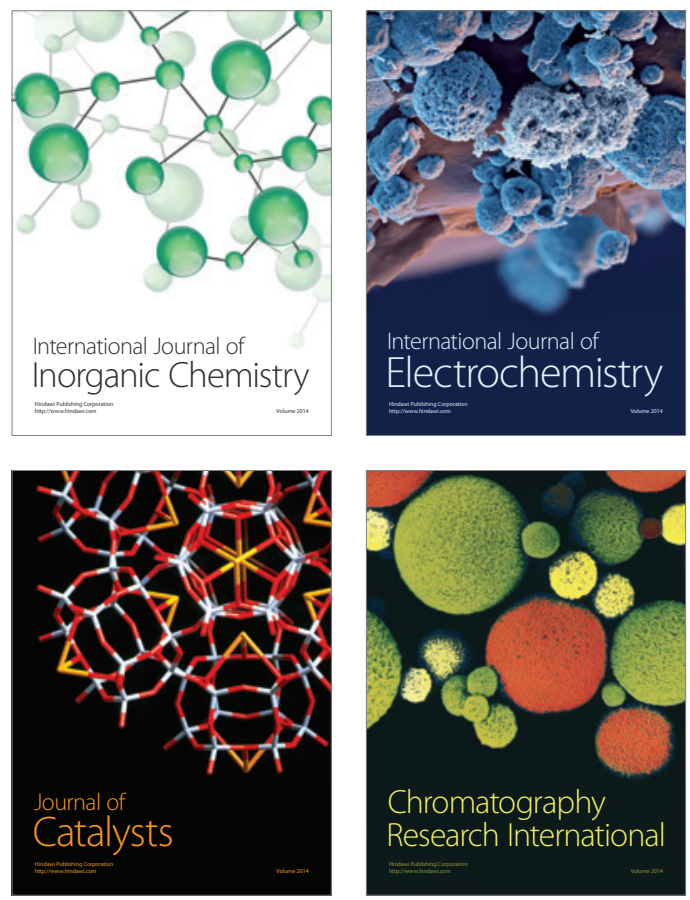
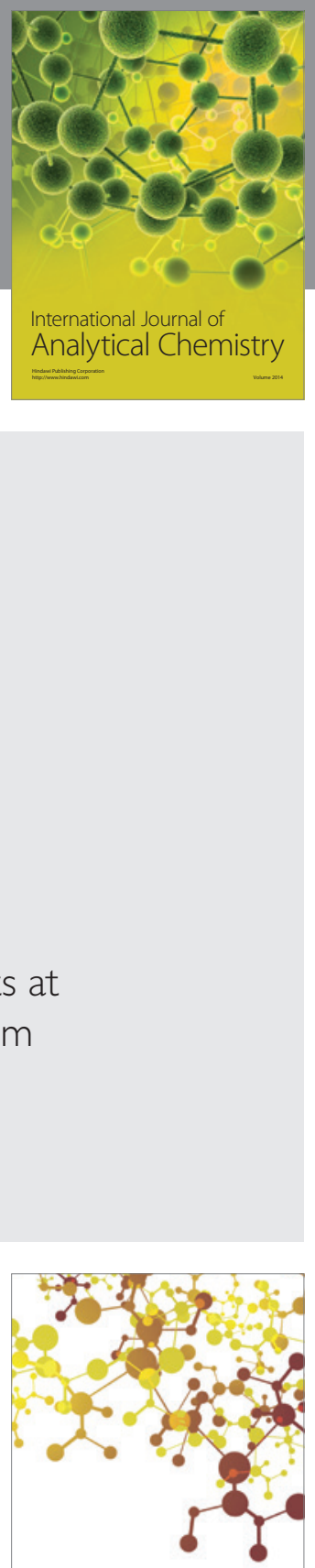

Journal of

Applied Chemistry
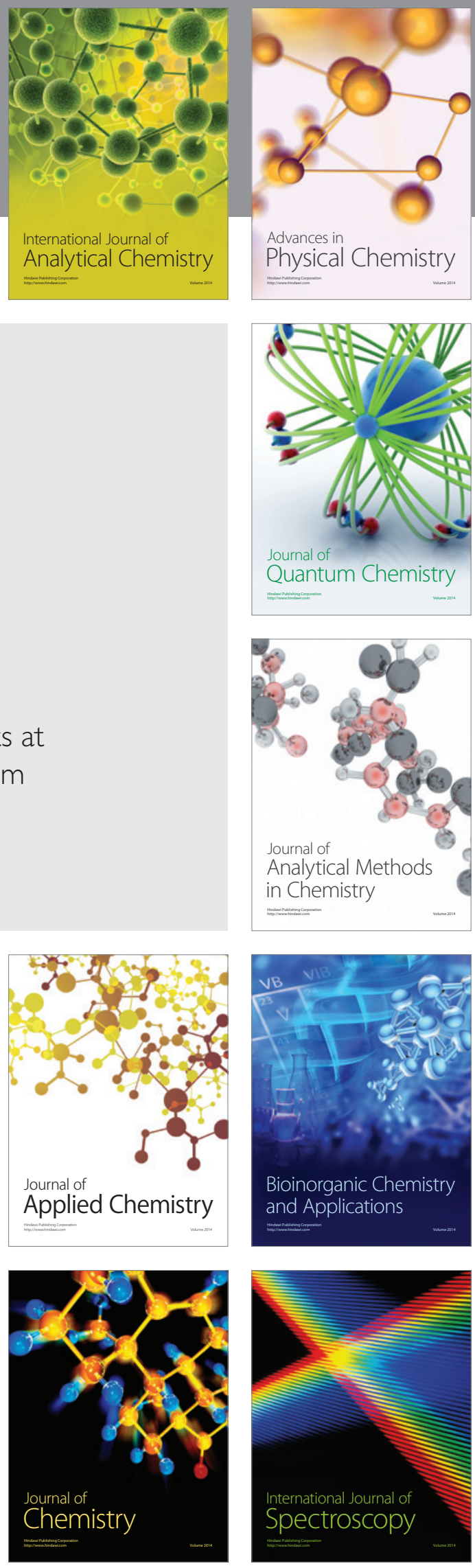